\title{
ANÁlISE DE CUSTO DE PRODUÇÃO, RECRIA E ENGORDA PELO MÉTODO DE CUSTEIO VARIÁVEL: UM ESTUDO EM UMA FAZENDA EM SAPEZAL - MT
}

\author{
Flavio dos Santos Negrão ${ }^{1}$ \\ Marcelo Evandro Alves 2
}

\section{Resumo}

O presente trabalho teve por objetivo analisar o custo de produção, engorda em confinamento e da recria com suplementação a pasto, através da aplicação da metodologia do custeio variável. A partir desta metodologia procura-se avaliar o controle gerencial para a apuração dos custos reais de produção. Trata-se de um estudo de caso de natureza exploratório e descritivo com abordagem quantitativa. Inicialmente foi discutida a relevância da implantação desta metodologia como suporte para as tomadas de decisões em uma fazenda com cerca de 2000 animais na recria e 1243 animais no confinamento. As informações colhidas pela pesquisa conseguiram apontar a lucratividade gerada pelo confinamento dos animais e comparando o custo de produção da recria com a compra de garrotes para o confinamento.

Palavras-chave: Contabilidade Gerencial, Custo de Produção e Lucratividade.

\section{INTRODUÇÃO}

A criação de gado é um dos principais destaques do agronegócio brasileiro e no cenário mundial. O país ocupa o segundo lugar em relação ao maior rebanho efetivo do mundo, com cerca de 200 milhões de cabeça, e no ano de 2004 assumiu a liderança nas exportações, com um quinto da carne comercializada internacionalmente e vendas em mais de 180 países. Essa atividade proporciona o desenvolvimento de diversos segmentos lucrativos para o país, principalmente a produção de carne e leite que juntos atingiram R $\$ 67$ bilhões. (MINISTÉRIO DA AGRICULTURA,PECUARIA E ABASTECIMENTO, 2011).

A participação brasileira no mercado internacional vem crescendo, com destaque para a produção de carne bovina, suína e de frango. Ainda segundo o Ministério da Agricultura, até 2020, a expectativa é que a produção nacional de carnes suprirá $44,5 \%$ do mercado mundial. Já a carne de frango terá $48,1 \%$ das exportações mundiais e a participação da carne suína será de 14,2\%. Esses dados levam a crer que o Brasil pode manter posição de primeiro exportador mundial de carne bovina e de frango. E cabe ao Ministério da Agricultura, por intermédio da Secretaria de Defesa Agropecuária, regulamentar e controlar as exportações de mercadorias de origem animal, atestando sua qualidade e segurança, fazendo inspeção

\footnotetext{
${ }^{1}$ Acadêmico do curso de Ciências Contábeis da UNEMAT - Campus de Tangará da Serra, flaviocont@hotmail.com

${ }^{2}$ Professor do Departamento de Ciências da UNEMAT - Campus de Tangará da Serra, marcelo.evandro@unemat.br
} 
industrial e sanitária para atender a sanidade exigida pelo país importadores (MINISTÉRIO DA AGRICULTURA,PECUARIA E ABASTECIMENTO, 2011).

A lucratividade na pecuária de corte depende tanto do que é consumido quanto do que é produzido pelos animais e o custo de fornecimento de alimentos torna-se um dos maiores gastos do sistema de produção. Os resíduos de soja e milho, antes descartados ou vendidos a um preço muito baixo, atualmente compõem a ração fornecida aos animais, possibilitando redução no custo com a alimentação. Muitas fazendas da região de Sapezal utilizam o confinamento como estratégia alternativa para terminar a engorda dos animais no período de seca. O cenário vem sendo modificado, uma vez que as fazendas realizam o processo de confinamento de forma intensiva visando atender o mercado nacional e internacional.

$\mathrm{Na}$ atividade rural, se pode concluir que quanto maior o rebanho menor será os custos fixos por unidade, uma vez que os custos acabam sendo divididos pela quantidade de unidades do processo de criação (MARION, 2005). Já em se tratando de custos variáveis ocorre alteração de acordo com a proporção da quantidade produzida. Diante do exposto, este estudo tem como objetivo analisar o custo de produção, recria e engorda pelo método do custeio variável em uma fazenda em Sapezal.

A contribuição desse trabalho para o setor reside no fato de que o custo de produção do gado é o que mais influencia na lucratividade da produção, devendo assim buscar analisar aspectos que possibilitem a redução do custo em cada método de engorda, resultando em maior rentabilidade do rebanho, uma vez que o preço de venda é determinado pelo mercado.

\section{REFERENCIAL TEÓRICO}

\subsection{Custos fixos e variáveis}

A conceituação de contabilidade de custos congrega os princípios e normas que possibilitam registro e o controle do processo de produção, agregando bens, serviços e demais gastos, elementos que estruturam valores e que acabam refletindo na posição patrimonial quanto à geração de estoques, contribuindo para a contabilidade gerencial e gerando informações úteis a tomada de decisão (HERNANDEZ, 2003; LEONE, 1996; OLIVEIRA, 2005).

É imprescindível para o gestor conhecer o custo real de cada lote ou do rebanho a qualquer momento, não só para apurar a rentabilidade após a venda, mas também para determinar o ponto ótimo de venda, ou seja, não manter o gado quando os custos passam a ser 
maiores que o ganho de peso (ou mantê-lo se o preço de mercado está baixo) (MARION, 2005).

Os custos fixos são aqueles que dependem da manutenção da estrutura positiva da empresa, independente da quantidade que venha a ser produzida, considerando o limite da capacidade instalada ( MEGLIORINI, 2007; OLIVEIRA, 2005). Os custos variáveis possuem uma relação direta com o volume da produção, aumentando ou diminuindo a medida que se aumenta ou diminui a quantidade produzida . (MEGLIORINI, 2007; OLIVEIRA, 2005).

O sistema de custos pelo custeio variável não é aceito pelo legislação fiscal, e serve somente para fins gerenciais, para tal é utilizado o custo de absorção conforme o Decreto 3.000/99. Neste método todos os gastos relativos ao esforço de produção são distribuídos para todos os animais produzidos, pouco importando se estes são fixos ou variáveis. Mesmo não sendo aceito pela legislação fiscal, o custeio variável apresenta vantagens sobre as demais, tais como: o resultado operacional em função das vendas; não há necessidade de adotar critérios de rateio para apropriar custos fixos; torna evidente a margem de contribuição de cada produto, muito utilizada no processo decisório (JANCULA, 2011).

\subsection{Custeio Variável}

O custeio variável consiste na apropriação dos custos variáveis, sejam diretos ou indiretos aos produtos em desenvolvimento, sendo o tratamento dado aos custos fixos é tornalos despesas do período . (MARTINS, 2003; MEGLIORINI, 2007; OLIVEIRA, 2005). O método do custeio variável torna-se útil em se tratando de aspectos de análise gerencial uma vez que não apropria custos fixos aos produtos, podendo assim identificar qual produto é mais rentável, verificando-se a necessidade de se produzir ou comprar um item ( matéria prima distinta), definindo um valor mínimo a ser praticado (MEGLIORINI, 2007).

De acordo com Crepaldi (1998) o custo histórico como base de valor não fornece ferramentas para subsidiar tomadas de decisões e com isso fica interessante apuração do custo corrigido que proporcionam dados mais reais. Esses dados podem favorecer na elaboração e no controle de orçamentos, tendo um maior controle nos custos fixos e favorecendo o controle gerencial. Por outro lado, o custeio variável não é aceito pelo fisco no Brasil, mas para efeitos de tributação ele pode ser ajustado no final do período, de forma a atender as exigências fiscais.

\subsection{Margem de Contribuição}


Megliorini (2007) e Oliveira (2005) citam que a margem de contribuição é a diferença entre o preço de venda de produto e seus custos e despesas variáveis, ou seja, é o restante excedente das despesas e custos gerados pela produção e venda do produto. Sendo assim, margem de contribuição deverá superar as despesas e os custos fixos para que a empresa comece a gerar lucro, assim, administração da empresa precisará então trabalhar de forma a baixar suas despesas e custos variáveis para que a empresa possa trabalhar com uma margem de contribuição maior para cobrir seus custos e despesas fixas. Com base na margem de contribuição pode se identificar qual produto é mais lucrativo, ou qual deles mais contribui para o abatimento das despesas e custos fixos, ou até mesmo para observar qual produto ou mercadoria não compensa produzir. Isso faz com que a análise da margem de contribuição seja ótima ferramenta para a tomada de decisões.

Ainda com base em Megliorini (2007) e Oliveira (2005), se houver a quebra de uma máquina ou até mesmo falta de matéria prima, caso a empresa trabalhe com dois ou mais produto tem que se conhecer a margem de contribuição pelos fatores limitantes para que possa, caso haja a necessidade, priorizar a produção de algum item que lhe de uma maior margem de contribuição.

De acordo com Lobrigatti (2004, p. 5) "o termo margem de contribuição tem um significado igual ao termo ganho bruto sobre as vendas. Isso indica para o empresário o quanto sobra das vendas para que a empresa possa pagar suas despesas fixas e gerar lucro". Lobrigatti (2004) descreve também que é fundamental para a empresa conhecer a margem de contribuição antes que as vendas sejam realizadas, pois é importante para o seu planejamento.

\subsection{Ponto de equilíbrio e margem de segurança}

Segundo dados do Serviço Brasileiro de Apoio as Micros e Pequenas Empresas (SEBRAE), $27 \%$ das empresas paulistas fecharam antes de completar um ano de funcionamento. Isso se dá pelo fato da empresa não conhecer seus custos e despesas ou até mesmo o mercado, e com isso não se planejaram. A empresa necessita conhecer seus gastos para que saiba a quantidade de vendas a serem feitas para que não tenha prejuízo (ESTADÃO, 2010).

De acordo com Megliorini (2007) e Hernandez (2003) o ponto de equilíbrio é a situação em que a empresa não apresenta nem lucro nem prejuízo, ou seja, a quantidade vendida atingirá o mesmo valor que os custos e despesas fixas e variáveis. Conhecendo a fórmula de encontrar o ponto de equilíbrio, o empresário poderá tomar decisões sobre redução 
ou aumento das atividades, preço e até dos custos. Em outras palavras, ocorre o ponto de equilíbrio quando a margem de contribuição cobre as despesas e custos fixos, sem que haja sobras de valor. Assim sendo seria necessário o empresário identificar quantos produtos seriam necessário para igualar o montante de seus gastos fixos. Megliorini (2007) menciona ainda que existem três situações de equilíbrio, o ponto de equilíbrio contábil, o econômico e o financeiro.

No Ponto de equilíbrio contábil a margem de contribuição deverá cobrir os custos e despesas fixas não levando em consideração o custo de oportunidade, mas incluindo as depreciações. Para o ponto de equilíbrio econômico é utilizado, além dos custos e despesas mencionados no ponto de equilíbrio contábil, o custo de oportunidade. Já o Ponto de equilíbrio financeiro é considerado apenas os gastos que gerarem desembolso, não considerando então o custo de oportunidade nem a depreciação (NASCIMENTO, 2001).Ainda de acordo com Nascimento (2001, p. 283), "a análise do ponto de equilíbrio é por natureza estática e indica uma situação econômica para determinado nível de produção e período, em circunstância as quais a receita total é igual ao custo total”.

Para Martins (2003), “a margem de segurança operacional corresponde a quantidade de produtos ou de receitas operadas acima do ponto de equilíbrio". A melhor forma de verificar se a empresa esta tendo ganho esperado é através da taxa de retorno, que é lucro antes do imposto de renda e antes da despesa financeira, dividido pelo total do ativo (MEGLIORINI,2007, p. 135).

\section{METODOLOGIA}

Esta pesquisa foi de natureza exploratória e descritiva, com a abordagem quantitativa e teve como estratégia de pesquisa o estudo de caso. O estudo foi realizado na Fazenda Bigolin de propriedade de Natalino Bigolin, localizada na Estrada Nova Fronteira km 80 mais 20 km à direita, no município de Sapezal - MT, estado de Mato Grosso, no período de fevereiro de 2010 a agosto de 2011. As informações foram, coletadas diretamente com funcionários e o proprietário da fazenda por meio de entrevistas, roteiros estruturados em planilhas de custo e planilha de controles da fazenda. O levantamento foi feito com base em 2000 cabeças de gado na recria e 1243 animais no confinamento, evidenciando o ganho de peso e os custos, no período referenciado. Foi demonstrado nos custos fixos e variáveis do confinamento apenas os animais que já haviam sido abatidos, ou seja, foi utilizados apenas os custos proporcionais aos animais abatidos. 
No decorrer da pesquisa levantou-se o imobilizado da empresa, separando-se o que é utilizado no confinamento e na recria, afim de conhecer as ferramentas e equipamentos utilizados no dia-a-dia da fazenda. Através de pesquisa, foi levantado o valor de mercado dos bens, o que para fins gerenciais é mais interessante, já que a empresa trabalha com valores reais e atualizados em seu sistema de custeio e por não haver registros anteriores, o valor contábil é desconhecido. Este levantamento encontra-se na tabela 1 e 2 do presente trabalho.

\section{Tabela 1. Valores Imobilizado Fazenda (Recria)}

\begin{tabular}{l|l|c|r}
\hline Quant. & Descrição & Valor contábil & \multicolumn{1}{|c}{ Valor de Mercado } \\
\hline 1 & Cerca de arame Liso & - & $200.000,00$ \\
\hline 1 & Curral de Madeira com Balança & - & $30.000,00$ \\
\hline 1 & Casa para Funcionários & - & $30.000,00$ \\
\hline 1 & Terreno 980 hectares & - & $5.586 .000,00$ \\
\hline 12 & Pastagem & - & $180.000,00$ \\
\hline 1 & Casale (Equipamento p/ tratar animais) & - & $35.000,00$ \\
\hline 8 & Trator & - & $30.000,00$ \\
\hline 1 & Animais de monta & - & $8.000,00$ \\
\hline 1 & Roda D’agua & - & $7.000,00$ \\
\hline 12 & Bebedouros e encanamento & & $60.000,00$ \\
\hline Total do Imobilizado & $\mathbf{6 . 1 4 6 . 0 0 0 , 0 0}$ \\
\hline
\end{tabular}

Fonte: Pesquisa de campo

A recria dos animais é feita na parte dos fundos da fazenda, localizada a aproximadamente $4 \mathrm{~km}$ da sede, e por isso a necessidade de haver dois currais na propriedade, assim, fica um curral em cada área, um na recria e outro no confinamento, já que os animais confinados ficam ao lado da sede da empresa, para facilitar o armazenamento dos alimentos a ser servido aos animais.

Tabela 2. Valores imobilizado Fazenda (Confinamento)

\begin{tabular}{l|l|r|r}
\hline Quant. & Descrição & Valor contábil & \multicolumn{1}{|c}{ Valor de Mercado } \\
\hline 1 & Kum (Equipamento p/ tratar animais) & - & $100.000,00$ \\
\hline 1 & Trator MF 292 & - & $30.000,00$ \\
\hline 1 & Trator MF 292 com Concha & - & $35.000,00$ \\
\hline 1 & Terreno 2 Hectares) & - & $11.400,00$ \\
\hline 1 & Barracão para armazenagem de ração & - & $100.000,00$ \\
\hline 1 & Triturador & - & $30.000,00$ \\
\hline 1 & Curral de madeira & - & $30.000,00$ \\
\hline 1 & Área estrutural do confinamento & $\mathbf{3 7 1 . 4 0 0 , 0 0}$ \\
\hline Total do Imobilizado & & $-000,00$ \\
\hline
\end{tabular}


Fonte: pesquisa de campo

\section{DISCUSSÃO DOS RESULTADOS}

A Fazenda Bigolin trabalha em sua grande maioria de extensão de terras com a agricultura, onde cultiva cerca de 4.300 hectares de soja, na safrinha, período que vai de março a agosto, planta cerca de 3.000 hectares de milho e ainda existe uma área de 270 hectares com pivô central, onde é cultivado feijão. Nas áreas ao fundo da fazenda é feita uma integração lavoura pecuária, onde é feita uma rotatividade de cultura, lavoura e pasto, a cada 3 anos. Esse processo torna-se favorável para o plantio da soja, já que o capim funciona muito bem como cobertura do solo, e é viável para o plantio do capim já que o pasto torna-se mais limpo, além de aproveitar a fertilidade do solo com resíduos da adubação da soja.

De março de 2010 à março de 2011 a fazenda operou com 980 hectares de pastagem, dividas em três tipos de capim; o brizantan, a braquiária ruzinienses e o tanzânia. Em função da rotatividade de cultura, os pastos são subdivididos em 12 áreas extensas que variam de 50 à 120 hectares, de acordo com os cortes de talhões utilizados anteriormente na agricultura. Nesse processo é utilizado cerca de dois animais por hectare, conforme recomendação do médico veterinário da Tortuga empresa fornecedora de insumos que presta assistência na fazenda gratuitamente, e por isso não agregará custo no processo.

Os animais da propriedade são todos rastreados e isso possibilita o consumidor conhecer "a vida pregressa" dos produtos e identificar os possíveis perigos à saúde coletiva a que foram expostos durante a sua produção e distribuição. Esses registros permitem identificar até mesmo a origem das matérias-primas e insumos utilizados na produção. $\mathrm{O}$ serviço de rastreabilidade da cadeia produtiva de bovinos e bubalinos (SISBOV), criado e mantido pelo Ministério da Agricultura, registra e controla todo o processo produtivo dos animais no Brasil. Já o serviço de estabelecimentos registrados no SIF é um aplicativo que permite identificar o frigorífico de origem dos produtos embalados in natura ou dos derivados de origem animal(MINISTÉRIO DA AGRICULTURA, PECUARIA E ABASTECIMENTO, 2011).

A tabela 3 apresenta os valores de depreciação dos bens da empresa, que foram usados como parte dos valores que compuseram os custos de cada atividade. As taxas de depreciação utilizadas no estudo seguem as sugeridas por Marion (2006).

Tabela 3. Valor das Depreciações do Imobilizado

\begin{tabular}{|l|l}
\hline Item & Taxa de Depreciação e Exautão \\
\hline
\end{tabular}




\begin{tabular}{l|c}
\hline & Anual \\
\hline Combinada rebocada (Kum e Casale) & $10 \%$ \\
\hline Trator MF 292 & $10 \%$ \\
\hline Trator MF 292 com Concha & $10 \%$ \\
\hline Barracão para Armazenagem de Ração & $4 \%$ \\
\hline Terreno & $4 \%$ \\
\hline Triturador & $6,67 \%$ \\
\hline Área estrutural do Confinamento & $10 \%$ \\
\hline Cerca de arame Liso & $10 \%$ \\
\hline Curral de Madeira com Balança & $4 \%$ \\
\hline Casa para Funcionários & $6,67 \%$ \\
\hline Pastagem & $20 \%$ \\
\hline Animais de monta & 12,5 \\
\hline Roda D’agua, Bebedouros e encanamento & $10 \%$ \\
\hline
\end{tabular}

Fonte: Adaptado de Marion (2006).

Partindo das taxas de depreciação foi possível levantar os custos mensais de cada um dos item acima. Porém não foi levado em consideração a exaustão da pastagem sugerida por Marion (2006), já que em função da rotatividade de lavoura pecuária a pastagem é substituída a cada 3 anos com uma média de exaustão de 33,33\% ao ano.

\subsection{Custos Recria}

Até o momento foi apontado no trabalho o valor do imobilizado da empresa e a tabela com a taxa de depreciação sugerida por Marion (2006). Partindo agora para a real parte de custos da produção na recria verifica-se que esse processo na fazenda dura um ano, quando os animais saem da pastagem e entram no processo de engorda no confinamento. Ver-se-à agora o levantamento da depreciação e exaustão dos imobilizados.

Tabela 4. Custo depreciação da recria

\begin{tabular}{c|l|r|r|r}
\hline Quant. & \multicolumn{1}{|c|}{ Descrição } & Valor de mercado & $\begin{array}{r}\text { Taxa depreciação } \\
\text { exaustão }\end{array}$ & $\begin{array}{c}\text { Valor } \\
\text { Depreciação }\end{array}$ \\
\hline 1 & Cerca de arame liso & $200.000,00$ & $10 \%$ & $20.000,00$ \\
\hline 1 & Curral de madeira com balança & $30.000,00$ & $4 \%$ & $1.200,00$ \\
\hline 1 & Casa para funcionários & $30.000,00$ & $6,67 \%$ & $2.001,00$ \\
\hline 1 & Terreno 980 hectares & $5.586 .000,00$ & $4 \%$ & $223.440,00$ \\
\hline 12 & Pastagem & $180.000,00$ & $33,33 \%$ & $59.994,00$ \\
\hline 1 & Casale (equipamento p/ tratar animais) & $15.000,00$ & $10 \%$ & $1.500,00$ \\
\hline 8 & Trator & $30.000,00$ & $10 \%$ & $3.000,00$ \\
\hline
\end{tabular}




\begin{tabular}{c|l|r|r|r}
\hline 1 & Animais de monta & $8.000,00$ & $12,50 \%$ & $1.000,00$ \\
\hline 1 & Roda D’água & $7.000,00$ & $10 \%$ & 700,00 \\
\hline 12 & Bebedouros e encanamentos & $60.000,00$ & $10 \%$ & $6.000,00$ \\
\hline \multicolumn{2}{l}{ Total do imobilizado } & $\mathbf{6 . 1 4 6 . 0 0 0 , 0 0}$ & & $\mathbf{3 1 8 . 8 3 5 , 0 0}$ \\
\hline
\end{tabular}

Fonte: Pesquisa de campo

Com base na tabela 4, pode-se verificar que o custo com depreciação e exaustão é relativamente alto, com valor de $\mathrm{R} \$ 318.835,00$, bem como o capital investido, que foi de $\mathrm{R} \$ 6.146 .000,00$. A Tabela 5 apresenta os custos variáveis do sistema de recria.

Tabela 5. Custos Variáveis da recria

\begin{tabular}{l|c|c}
\hline \multicolumn{1}{c}{ Descrição } & Valor total & Valor por cabeça \\
\hline Custo aquisição de animais & $1.500 .000,00$ & 750,00 \\
\hline Frete & $20.500,00$ & 10,25 \\
\hline Rastreabilidade & $9.360,00$ & 4,68 \\
\hline Vacina aftosa & $1.800,00$ & 0,90 \\
\hline Vacina carbúnculo & $1.163,20$ & 0,58 \\
\hline Vacina vermífugo & $18.072,00$ & 9,04 \\
\hline Vacina modificador orgânico & $2.016,00$ & 1,01 \\
\hline Vacina contra raiva & $2.400,00$ & 1,20 \\
\hline Silagem & $38.400,00$ & 19,20 \\
\hline Sal mineral foscarmos & $71.424,66$ & 35,71 \\
\hline Total custos variáveis & $\mathbf{1 . 6 6 5 . 1 3 5 , 8 6}$ & $\mathbf{8 3 2 , 5 7}$ \\
\hline
\end{tabular}

Fonte: Pesquisa de Campo

A sanidade de animais é controlada através de vacinação, que é feita três vezes ao ano, no caso do vermífugo, a qual sendo duas delas na campanha contra febre aftosa e uma na chegada dos animais na propriedade, onde também ocorre a vacinação com modificador orgânico. Já a vacina de raiva acontece uma vez ao ano e também efetuada na campanha. No período da seca, os animais recebem uma suplementação formada de $60 \mathrm{~g}$ de sal, com dois $\mathrm{kg}$ de silagem, a fim de que os animais não percam peso. Para que quando entrar o período chuvoso não estejam fracos e precisem recuperar peso para atingir o porte ideal que é de no mínimo $400 \mathrm{~kg}$ para entrarem no confinamento, sendo que, a quantidade de dias de confinamento varia de acordo com o peso de entrada dos animais. Os custos com a rastreabilidade dos animais são efetivados através do registro do documento de identificação animal (DIA) e as vistorias a cada seis meses.

Tabela 6. Custos fixos da recria 


\begin{tabular}{l|c|c}
\hline \multicolumn{2}{c}{ Custos fixos } \\
\hline Descrição & Valor total & Valor unitário \\
\hline Depreciação/ Exaustão & $318.835,00$ & 159,42 \\
\hline Salários e encargos & $53.943,00$ & 26,97 \\
\hline Combustível & $1.476,00$ & 0,74 \\
\hline Total custos fixos & $\mathbf{3 7 4 . 2 5 4 , 0 0}$ & $\mathbf{1 8 7 , 1 3}$ \\
\hline
\end{tabular}

Fonte: Pesquisa de Campo

O combustível gasto no trator entra como custo fixo, uma vez que o trajeto para tratar o animal é o mesmo, independente da quantidade de animal que tenha na área, já que os cochos estão alinhados na beira da cerca. Na propriedade tem um vaqueiro que toma conta do rebanho e recebe a ajuda de três funcionários nos períodos de vacinação e embarque e desembarque de animais, através de diárias. Além disso, completa os custos fixos a depreciação e a exaustão dos imobilizados.

Tabela 7. Comparativo fazenda Bigolin X Nogueira (2006)

\begin{tabular}{l|c|c}
\hline \multicolumn{2}{c}{ Comparativo fazenda Bigolin X Nogueira (2006) } \\
\hline Descrição & Fazenda Bigolin & Nogueira (2006) \\
\hline Custo do Garrote pronto para entrar em confinamento & 832,57 & 728,00 \\
\hline Custo de aquisição do Bezerro de 12 meses & 750,00 & 670,00 \\
\hline Custo unitário do garrote no Período & 82,57 & 58,00 \\
\hline
\end{tabular}

Fonte: Pesquisa de Campo

Em uma pesquisa no estado de São Paulo pela Scot Consultoria, Nogueira (2006), o custo de produção de um garrote de $420 \mathrm{Kg}$, no estado de São Paulo no ano de 2006, criado a pasto girava em torno de $\mathrm{R} \$ 728,00$ um preço bem inferior ao atingido pela Fazenda Bigolin, que foi de $\mathrm{R} \$ 832,57$. Conforme tabela 7 essa diferença se dá também pelo fato da compra do bezerro com 12 meses, que no caso de Nogueira (2006) o custo de aquisição era no valor de $\mathrm{R} \$ 670,00$ e no caso de Sapezal os custo do bezerro é de $\mathrm{R} \$ 750,00$. Isso mostra que a diferença de custo do processo menos o valor do animal foi pouco mais alto na fazenda Bigolin que foi de $\mathrm{R} \$ 82,57$ para $\mathrm{R} \$ 58,00$.

Após a conclusão do processo de recria, tem-se os garrotes com 24 meses no porte de colocar em confinamento. Normalmente esses animais têm um peso equivalente ou superior a $400 \mathrm{Kg}$, e são destinados ao confinamento para terminação da engorda.

\subsection{Custo de Confinamento}


Nogueira (2006) comenta que usar o confinamento como forma de engorda de bois com duração de cerca de 125 dias e ganho de peso em torno de $1,2 \mathrm{Kg} /$ dia, o custo total da diária do confinamento deve ser de $\mathrm{R} \$ 3,03$ por arroba e o custo da alimentação obteve um preço de $\mathrm{R} \$ 57,36$ por arroba engordada em confinamento. E que a estratégia de terminação da engorda em confinamento com animais entrando no confinamento com $420 \mathrm{Kg}$, levaria em torno de 61 dias para terminação e agregará aos animais 2,60 arrobas e o custo do animal pronto estaria em torno de $\mathrm{R} \$ 939,21$ e que o custo do animal ao entrar no confinamento era de $\mathrm{R} \$ 728,00$, custo esse que era da produção do gado a pasto.

Nogueira(2006) não trás em sua pesquisa a área e a quantidade de $\mathrm{m}^{2}$ para se confinar animais. Já na fazenda Bigolin, para o confinamento de garrotes é utilizado uma área de $40 \mathrm{~m}$ por 60 metros que dá uma área total de $2.400 \mathrm{~m}^{2}$, onde é colocado em torno de 170 animais e outras áreas de 40 metros por 40 metros aonde temos $1.600 \mathrm{~m}^{2}$, onde são tratados 114 animais. Isso gera uma média de $14 \mathrm{~m}^{2}$ por animal, que é o recomendado pelo veterinário que presta assistência. Existe na propriedade 12 piquetes com 6 bebedouros que ficam alocados entre os piquetes de uma forma que os animais dos dois piquetes consigam ter acesso a água, além disso existe 440 metros de cochos, onde são servidas a ração.

Para se iniciar o confinamento, houve investimento relativamente alto em imobilizado, com isso acarretou um alto custo com depreciação, conforme tabela 8.

Tabela 8. Depreciação imobilizado do confinamento

\begin{tabular}{c|l|c|c|c}
\hline Quant. & \multicolumn{1}{|c|}{ Descrição } & $\begin{array}{c}\text { Valor de } \\
\text { Mercado }\end{array}$ & $\begin{array}{c}\text { Taxa de depreciação } \\
\text { e exaustão }\end{array}$ & Valor depreciação \\
\hline 1 & Kum (Equipamento p/ tratar animais) & $100.000,00$ & $10 \%$ & $10.000,00$ \\
\hline 1 & Terreno de 2 hectares & $11.400,00$ & $4 \%$ & 456,00 \\
\hline 1 & Trator MF 292 & $30.000,00$ & $10 \%$ & $3.000,00$ \\
\hline 1 & Trator MF 292 com concha & $35.000,00$ & $10 \%$ & $3.500,00$ \\
\hline 1 & Barracão p/ armazenagem de ração & $100.000,00$ & $4 \%$ & $4.000,00$ \\
\hline 1 & Triturador & $15.000,00$ & $6,67 \%$ & 1000,50 \\
\hline 1 & Curral de madeira com balança & $30.000,00$ & $4 \%$ & $1.200,00$ \\
\hline 1 & Área estrutural do confinamento & $50.000,00$ & $10 \%$ & $5.000,00$ \\
\hline \multicolumn{2}{l|}{ Total do imobilizado } & $\mathbf{3 7 1 . 4 0 0 , 0 0}$ & & $\mathbf{2 8 . 1 5 6 , 5 0}$ \\
\hline
\end{tabular}

Fonte: Pesquisa de Campo

Nos finais de tarde e no amanhecer, os animais confinados ficam agitados e caso enrosquem-se na cerca, existe a possibilidade de óbitos. E para prevenir esse risco, o vaqueiro passa frequentemente pela área de confinamento nesses períodos. Segundo relatório da fazenda, os animais confinados seguem uma receita de alimentação com bastante fibra. E foi 
levantado a receita utilizada na fazenda, ao qual tem que haver uma adaptação dos animais à quantidade de ureia para que eles não venham a óbito, o que ocorreu em anos anteriores.

Tabela 9. Ração do Confinamento

\begin{tabular}{l|c|c|c}
\hline \multicolumn{4}{c}{ Custo para fabricação de 4000 Kg de ração } \\
\hline Produto & Kg & Valor tonelada & Valor ração \\
\hline Casquinha de Algodão & 250 & 69,00 & 17,25 \\
\hline Caroço de Algodão & 110 & 250,00 & 27,50 \\
\hline Silagem & 1940 & 80,00 & 155,20 \\
\hline Farelo de soja & 150 & 570,00 & 85,50 \\
\hline Resíduo de Soja & 285 & 200,00 & 57,00 \\
\hline Milho & 1195 & 300,00 & 357,00 \\
\hline Ureia & 15 & $1.132,00$ & 16,98 \\
\hline Sal & 60 & $1.917,00$ & 115,02 \\
\hline Custo total da ração & & & $\mathbf{8 3 1 , 4 5}$ \\
\hline
\end{tabular}

Fonte: Pesquisa de campo

A receita de alimentação dos animais, conforme observado na tabela 9 é relativamente baixa, já que cada animal consome em média de 18,74 Kg de ração por dia, o que dá um custo diário de $\mathrm{R}$ \$ 3,90 por animal, e um ganho em torno de 1,23 kg por dia e o preço da arroba do animal, como pode-se ver na apêndice, pode-se já presumir que é vantajoso confinar. Confrontando o resultado com Nogueira (2006), pode-se observar que o custo da alimentação dos animais para se atingir uma arroba leva em torno de 12,22 dias, que gera um custo de $\mathrm{R} \$ 47,59$ por arroba, uma economia de $\mathrm{R} \$ 9,77$ por arroba em relação aos $\mathrm{R} \$ 57,36$ encontrado por ele. Vale lembrar que Nogueira não apresentou receita utilizada, já em se tratando de ganho de peso por dia, os dois trabalho obtiveram praticamente o mesmo resultado, $1,2 \mathrm{~kg}$ de Nogueira (2006) e 1,23 kg na fazenda em Sapezal.

Tabela 10. Custos Variáveis do confinamento

\begin{tabular}{l|c|c}
\hline \multicolumn{3}{c}{ Custos Variáveis } \\
\hline Descrição & Valor total & Valor por cabeça \\
\hline Ração animal & $309.022,74$ & 248,61 \\
\hline Custo garrote & $1.034 .884,51$ & 832,57 \\
\hline Energia elétrica & 987,00 & 0,79 \\
\hline Total custos variáveis & $\mathbf{1 . 3 4 4 . 8 8 4 , 5 1}$ & $\mathbf{1 . 0 8 1 , 9 7}$ \\
\hline
\end{tabular}

Fonte: Pesquisa de campo

Em se tratando de confinamento, os maiores custos são sempre os custos variáveis, já que englobam os custos de entrada dos animais e o custo com a alimentação dos mesmos, mas não podemos desconsiderar os custos fixos, conforme tabela 11. 
Tabela 11. Custos fixos do confinamento

\begin{tabular}{l|c|c}
\hline \multicolumn{1}{c|}{ Descrição } & Valor total & Valor por cabeça \\
\hline Depreciação & $17.499,26$ & 13,85 \\
\hline Salários e encargos & $7.192,40$ & 5,79 \\
\hline Combustíveis & $1.968,00$ & 1,58 \\
\hline Total de Custos fixos & $\mathbf{2 6 . 6 5 9 , 6 6}$ & $\mathbf{2 1 , 4 5}$ \\
\hline
\end{tabular}

Fonte: Pesquisa de campo

A parte dos custos fixos que mais influência no resultado do confinamento, como demonstrado na tabela 11, é a depreciação, pois existe um alto investimento para se iniciar a produção. O custo com salário corresponde a 80 dias, já que o confinamento desses animais durou apenas por esse período, e foi levado em consideração os encargos sobre salário, conforme Megliorini (2007). Além desse processo, tem-se também o custo com combustível, que é utilizado nos maquinários para tratar os animais, custo este considerado fixo, já que os piquetes ficam alinhados em um corredor e para fazer o retorno tem que percorrer toda a extensão, independente da quantidade existente nos piquetes ou se algum piquete encontra-se vazio.

Tabela 12. Comparativo Fazenda Bigolin X Nogueira (2006)

\begin{tabular}{l|c|c}
\hline \multicolumn{2}{c}{ Comparativo Fazenda Bigolin X Nogueira (2006) } \\
\hline \multicolumn{1}{c|}{ Descrição } & Fazenda Bigolin & Nogueira (2006) \\
\hline Custo de entrada do garrote p/ confinamento & $\mathrm{R} \$ 832,57$ & $\mathrm{R} \$ 728,00$ \\
\hline Custo do garrote por dia de confinamento & $\mathrm{R} \$ 4,17$ & $\mathrm{R} \$ 3,46$ \\
\hline Ganho de peso de animal por dia & $1,23 \mathrm{Kg}$ & $\mathrm{1,2} \mathrm{Kg}$ \\
\hline Custo do boi para abate & $\mathrm{R} \$ 1.081,97$ & $\mathrm{R} 939,21$ \\
\hline
\end{tabular}

Fonte: pesquisa de campo

Conforme tabela 12, o custo do boi confinado chegou a $\mathrm{R} \$ 1.081,97$ e foi muito superior ao custo apresentado por Nogueira (2006), que foi de R $\$ 939,21$ e, levando em consideração que os animais entraram em confinamento com custo de $\mathrm{R} \$ 728,00$ cada animal custou por dia $\mathrm{R} \$ 3,46$ enquanto na fazenda aqui estudada obteve um custo de $\mathrm{R} \$ 4,17$ por dia já que o animal entrou em confinamento com um custo de R\$832,57. A seguir uma demonstração do rendimento dos animais em confinamento.

O ganho de peso dos animais em confinamento, como pode ser visto na apêndice, foi em média 1,23 kg por dia, mas com uma diferença do lote 9 para os demais lotes, isso ocorreu pelo fato de um erro no transporte dos animais que, ao chegar atrasado para o abate, foram mantidos num piquete até o dia seguinte, completando mais de 30 horas sem comer e beber, 
além do stress pela viagem, o que fez com que os animais perdessem peso, que não pode ser calculado. Pode ser visto na apêndice, a receita dos animais confinados que será utilizado na tabela 13 para demonstrar a margem de contribuição dos animais.

Tabela 13. Margem de contribuição

\begin{tabular}{rlc}
\hline \multicolumn{1}{c|}{ Descrição } & Total \\
\hline 1. & Quantidade vendida & $1.243,00$ \\
\hline 2. & Preço de venda unitário & $1.999,23$ \\
\hline 3. & Receita de venda (1x2) & $2.485 .045,70$ \\
\hline 4. & Custos Variáveis Unitários & $1.081,97$ \\
\hline 5. & Custo variável Total (1x4) & $1.344 .884,51$ \\
\hline 6. & Margem de contribuição (3-5) & $\mathbf{1 . 1 4 0 . 1 6 1 , 1 9}$ \\
\hline 7. & Custos e despesas fixos (Recria e confinamento) & $259.258,52$ \\
\hline 8. & Lucro Operacional dos lotes (6-7) & $\mathbf{8 8 0 . 9 0 2 , 6 7}$ \\
\hline
\end{tabular}

Fonte: Adaptado Megliorini

A margem de contribuição como demonstrado na tabela 13 foi de $\mathrm{R} \$ 1.140 .161,19$ ou seja, cada animal contribui com $\mathrm{R} \$ 917,27$ para cobrir os custos fixos. Além disso, demostra um lucro operacional de $\mathrm{R} \$ 880.902,52$ e, com os dados acima expostos pode-se encontrar o ponte de equilíbrio e a margem de segurança.

Tabela 14. Ponto de equilíbrio

\begin{tabular}{l|c}
\hline 1. Custos fixos & $259.258,52$ \\
\hline 2. Preço de venda unitário por cabeça & $1.999,23$ \\
\hline 3. Custos e despesas variáveis unitária & $1.081,97$ \\
\hline 4. Ponto de equilíbrio $=1 /(2-3)$ & 282,64 \\
\hline Fonte: pesquisa de &
\end{tabular}

Fonte: pesquisa de campo

Levando em consideração que cada animal foi vendido em média $\mathrm{R} \$ 1.999,23 \mathrm{e}$ pesou em média 21,79 arrobas, pode-se falar que o ponto de equilíbrio se dá quando atingir $6.158,82$ arrobas, representado por 282,64 animais. E a Margem de segurança corresponde a 1.243 animais vendidos menos o ponto de equilíbrio que é 282,64 animais, que dá uma margem de segurança de 960,36 animais, ou se tratando em arrobas, daria 20.926,15@.

\section{Considerações Finais}

O conhecimento da área em que se quer trabalhar é o primeiro passo para se conseguir chegar ao resultado desejado, buscar pessoas capacitadas e engajadas no processo de produção é fundamental, além disso deve se planejar o que fazer e como fazer o processo 
produtivo, e para isso é de suma importância conhecer os seu custos, para calcular a viabilidade de mercado e do investimento.

Neste caso foi aplicado um exemplo de um sistema de recria e confinamento, o que beneficiou no levantamento dos custos fixos e variáveis. Porém, em cada caso de confinamento deve ser analisado de forma diferente, já que a parte de alimentação do gado deve ser formulada com base na produção agrícola da região, o que variaria o custo da receita. Outra dificuldade é em relação ao custo da ureia, já que ela é cotada em dólar e varia diariamente. Tornam-se necessárias novas pesquisa sobre o assunto e com novas receitas de alimentação.

Assim conclui-se que o objetivo foi alcançado, ao levantar o lucro do confinamento, que proporcionou uma margem de lucro de $35,45 \%$ sobre a receita realizada. Pode se observar também que o custo do garrote ao entrar em confinamento é muito alto, e se conseguindo diminuir esse custo, a empresa poderia obter um lucro maior. Esse custo poderia ser baixado até mesmo na hora de compra do bezerro para a recria.

\section{Referências bibliográficas}

CREPALDI, Silvio Aparecido. Contabilidade Rural : uma abordagem decisória - 2. Ed. Revista atualizada e aplicada - São Paulo: Atlas, 1998.

ESTADÃO. Economia \& Negócios. Disponível em:

<<http://economia.estadao.com.br/noticias/economia\%2csebrae-27-das-empresas-de-sp-fechamno-1-ano\%2c33011\%2c0.htm >. Acesso em 13/10/2011.

HERNANDEZ PEREZ JUNIOR, José. Gestão Estratégica de custo / José Hernandez Peres Junior, Luis Martins de Oliveira, Rogério Guedes Costa. - 3. Ed. - São Paulo: Atlas, 2003.

JANCULA, Jonatan de Sousa . PORTAL DA CONTABILIDADE. Custos fixos e variaveis. Disponível em: http://www.portaldecontabilidade.com.br/tematicas/custo-fixo-variavel.htm> acesso em: 10/09/2011.

LEONE, George S. G. Curso de contabilidade de custos. São Paulo: Atlas, 1996

LOBRIGATTI, Luiz Albert Fernandes. Margem de Contribuição: Quantos sobra para sua empresa? FIN/ Agosto de 2004. $2^{\mathrm{a}}$ Ed. $1^{\circ} 4^{\circ} \mathrm{M}$. Disponível em > http://www.biblioteca.sebrae.com.br/bds/BDS.nsf/E809A7FF3D9553E90325714700620C06/ \$File/NT000AFB26.pdf. Acesso em 24 set. 2010.

MARION, José Carlos. Contabilidade Rural: contabilidade agrícola, contabilidade da pecuária, imposto de renda pessoa jurídica. 8. Ed. - São Paulo : Atlas, 2006. 
MARTINS, Eliseu. Contabilidade de Custos - 8. ed. - São Paulo : Atlas, 2001.

MARTINS, Eliseu. Contabilidade de custos. 9. ed. São Paulo : Atlas, 2003.

MEGLIORINI, Evandir. Custos: analise e gestão. 2 ed. São Paulo: Pearson Prentice Hall, 2007.

MINISTÉRIO DA AGRICULTURA, PECUARIA E ABASTECIMENTO. Bovinos e

Bubalinos. Disponível em: <http://www.agricultura.gov.br/animal/especies/bovinos-ebubalinos> acesso em:15/09/2011.

MINISTÉRIO DA AGRICULTURA, PECUARIA E ABASTECIMENTO. Exportação.

Disponível em:<http://www.agricultura.gov.br/animal/exportacao >. Acesso em 15/09/2011.

MINISTÉRIO DA AGRICULTURA, PECUARIA E ABASTECIMENTO. Rastreabilidade.

Disponível em: <http://www.agricultura.gov.br/animal/rastreabilidade > acesso em:15/09/2011.

NASCIMENTO, Jonilton Mendes do. Custo : planejamento, controle e gestão na economia globalizada- 2 ed. - São Paulo: Atlas, 2001.

NOGUEIRA, Mauricio Pauma. Custos e viabilidade de confinamento frente aos preços baixos (2006). Disponível em:

<http://www.coanconsultoria.com.br/images/palestras/Custos\%20e\%20viabilidade\%20do\%2 0confinamento.pdf >. Acesso em 20/10/2011.

OLIVEIRA, Luis Martins de. Contabilidade de custo para não Contadores . 2. Ed. São Paulo : Atlas, 2005.

PEREZ JUNIOR, José Hernandez. Gestão Estratégica de custo 3. Ed. - São Paulo: Atlas, 2003. 
Apêndice.

Tabela 15. Rentabilidade dos lotes do confinamento

\begin{tabular}{|c|c|c|c|c|c|c|c|c|c|}
\hline Lote & $\begin{array}{l}\text { Quantidade } \\
\text { De animais }\end{array}$ & $\begin{array}{l}\text { Dias de } \\
\text { Confinament } \\
\text { o }\end{array}$ & $\begin{array}{l}\text { Peso de } \\
\text { Entrada }\end{array}$ & $\begin{array}{l}\text { Consumo } \\
\text { de ração Kg }\end{array}$ & $\begin{array}{l}\text { Peso } \\
\text { Saída }\end{array}$ & $\begin{array}{l}\text { Ganho de } \\
\text { Peso dia }\end{array}$ & $\begin{array}{l}\text { Rendimento } \\
\text { de carcaça \% }\end{array}$ & $\begin{array}{l}\text { Valor } \\
\text { arroba }\end{array}$ & $\begin{array}{l}\text { Receita } \\
\text { Total }\end{array}$ \\
\hline 7 & 170 & 53 & 515 & $174.433,00$ & 572,10 & 1,08 & 56,41 & 94,00 & $335.328,33$ \\
\hline 6 & 170 & 54 & 521 & $177.846,00$ & 580,20 & 1,10 & 57,66 & 93,00 & $332.401,36$ \\
\hline 5 & 170 & 55 & 522 & $181.146,00$ & 591,50 & 1,26 & 56,70 & 90,00 & $349.596,36$ \\
\hline 4 & 170 & 56 & 515 & $184.104,00$ & 596,50 & 1,46 & 56,27 & 90,00 & $342.380,41$ \\
\hline 3 & 112 & 57 & 521 & $124.966,00$ & 592,40 & 1,25 & 56,74 & 92,00 & $225.725,40$ \\
\hline 8 & 113 & 77 & 448 & $159.509,67$ & 582,20 & 1,75 & 57,47 & 94,00 & 235.258 .38 \\
\hline 9 & 113 & 78 & 497 & $160.251,11$ & 558,76 & 0,79 & 57,99 & 93,00 & $222.983,71$ \\
\hline 2 & 113 & 79 & 451 & $161.059,32$ & 543,10 & 1,17 & 56,78 & 89,00 & $220.793,33$ \\
\hline 1 & 112 & 80 & 451 & $163.353,90$ & 547,14 & 1,20 & 59,97 & 91,00 & $220.218,42$ \\
\hline $\begin{array}{l}\text { Total e } \\
\text { média }\end{array}$ & 1.243 & 65 & 493 & $1.486 .669,00$ & 573,79 & 1,23 & 56,99 & 91,73 & $2.485 .045,70$ \\
\hline
\end{tabular}

Fonte: pesquisa de campo 